\title{
The Medusa faces of dyspnoea in COPD
}

\author{
Emiel F.M. Wouters
}

Affiliation: Dept Respiratory Diseases, Maastricht University Medical Center (MUMC+), Maastricht, The Netherlands. CIRO+, Center of Expertise for Organ Failure, Horn, The Netherlands.

Correspondence: Emiel F.M. Wouters, Maastricht University Medical Center, Dept Respiratory Diseases, PO Box 5800, 6202 AZ Maastricht, The Netherlands. E-mail: e.woutersamumc.nl

@ERSpublications

Cardiopulmonary exercise testing is a very useful tool in understanding dyspnoea in COPD http://ow.ly/lHFb30oc7dY

Cite this article as: Wouters EFM. The Medusa faces of dyspnoea in COPD. Eur Respir J 2019; 53: 1900487 [https://doi.org/10.1183/13993003.00487-2019].

Exercise limitation and exertional dyspnoea are common problems in patients with a variety of chronic lung diseases, as well as with heart failure. In chronic obstructive pulmonary disease (COPD) patients, the level of patient-reported dyspnoea is used as a parameter to assess COPD, currently leading to a "one size fits all" approach, largely based on pharmacological recommendations [1]. As exertional symptoms poorly correlate even with resting measurement lung function clusters [2], a more accurate estimate of functional capacity by cardiopulmonary exercise testing (CPET) can provide information about the influences of the cardiac, respiratory, musculoskeletal and haematological systems [3]. Such assessment of the integrated cardiopulmonary response to exercise remains largely underutilised in the personalised assessment and management of patients with exercise limitation and breathlessness.

The collaboration of two expert teams on exercise pathophysiology has extended our understanding considerably of this disabling problem, through a set of studies on exercise limitation in COPD patients and those with COPD and heart failure overlap. Their report is published in this issue of the European Respiratory Journal [4].

Among ventilatory inefficiency measurements, the authors already reported that increases in the ventilation intercept in the plot of minute volume $\left(V^{\prime} \mathrm{E}\right)$ against carbon dioxide output $\left(V^{\prime} \mathrm{CO}_{2}\right)$ better expresses the progressive worsening on exercise ventilator inefficiency across the continuum of COPD severity and was related to greater mechanical constraints, worsening pulmonary gas exchange, higher dyspnoea scores and poorer exercise capacity. Significant ventilatory inefficiency was already found in very mild (Global Initiative for Chronic Obstructive Lung Disease stage 1) COPD patients, suggesting coexisting ventilation-perfusion abnormalities [5]. In another paper, both groups reported that heart failure with reduced left ventricular ejection fraction had discernible effects on selected physiological responses to exertion in patients with COPD: an unusually high ventilator response to metabolic demand (low $V^{\prime} \mathrm{E} / V^{\prime} \mathrm{CO}_{2}$ intercept, high $V^{\prime} \mathrm{E} /$ $V^{\prime} \mathrm{CO}_{2}$ slope and high peak $V^{\prime} \mathrm{E} / V^{\prime} \mathrm{CO}_{2}$ ratio) and low peak end-tidal partial pressure for $\mathrm{CO}_{2}$ values, reflecting alveolar hyperventilation and/or lung perfusion abnormalities, were more frequently reported in overlap than in COPD patients. A $V^{\prime} \mathrm{E} / V^{\prime} \mathrm{CO}_{2}$ intercept $\leqslant 3.5 \mathrm{~L} \cdot \mathrm{min}^{-1}$ seems to predict overlap patients [6].

In another paper, the same authors report that breathlessness and poor exercise tolerance in overlapping COPD-heart failure patients are strongly influenced by interpatient variability on respiratory centres' chemostimulation. Particularly, in the subgroup of patients with resting hypocapnia the excessive ventilation hastens dynamic abnormalities in pulmonary mechanics. Indeed, these patients had to overcome an enlarged physiological dead space to hyperventilate leading to dynamic hyperinflation, earlier 
mechanical constraints, greater dyspnoea and reduced exercise capacity. Conversely, those patients with normocapnia seem to opt not to fight and delay critical inspiratory constraints [7].

In COPD patients, the reported acute-on-chronic hyperinflation may result in a reduction in peripheral muscle blood flow due to the central haemodynamic consequences or cardiac output redistribution towards the overloaded respiratory muscles [8, 9]. In heart failure, low cardiac output, global sympathetically mediated vasoconstriction and microvascular abnormalities characteristically compromise appendicular muscle blood flow [10]. The Brazilian and Canadian researchers demonstrate that muscle blood flow impairment was markedly greater in overlap patients compared not only to COPD but also to heart failure patients. This reduced convective $\mathrm{O}_{2}$ delivery in overlap patients was accompanied by relatively greater fractional $\mathrm{O}_{2}$ extraction and higher blood lactate concentration [11].

Rocha et al. [4] report that impaired aerobic function, as primarily indicated by a low $\Delta V^{\prime} \mathrm{CO}_{2} / \Delta$ work rate during incremental CPET, discriminates a subgroup of patients with COPD-heart failure who are particularly symptomatic and disabled. This impaired aerobic function was associated with lower limits for tidal volume expansion, impaired gas exchange efficiency and a higher left ventricular end-diastolic diameter at rest, excessive exertional ventilation relative to the metabolic demand, higher operating lung volumes leading to earlier attainment of critical inspiratory constraints and a severely impaired peak aerobic capacity. These abnormalities were associated with higher leg discomfort and breathlessness during rest and on exertion [12]. Mesquita et al. [13] previously reported that this impaired exercise performance in overlap patients was associated with weaker quadriceps muscles and more symptoms of anxiety and depression than in those with normal cardiac function.

The joint efforts of this pan-American research team clearly demonstrate that only the knowledge on the mechanisms leading to patient's disability is crucial to lessen symptom burden and improve the ability of the patients to cope with the demands of daily life [12]. Profound pathophysiological understanding of these mechanisms may guide the physician towards a more personalised management strategy. Instead of relying on integration of all physiological information provided by CPET, clinicians are satisfied by overall measurement of functional performance by field tests even to evaluate invasive interventions as surgical and endoscopic lung volume reduction procedures for emphysema [14].

Such systematic assessment of CPET measurements in COPD patients in general, and in overlap patients in particular, provides unique physiological information to offer a contemporary, personalised management to these patients [5]. Exercise ventilatory inefficiency may be a clinical important end-point in interventional trials in COPD. Clinicians must consider maximising deflational therapy, particularly in the overlap group, in order to attenuate the negative haemodynamic consequences of higher operating lung volumes in these patients. Identification of the subgroup of COPD-heart failure patients with excessive exertional ventilation may guide therapeutic and rehabilitative interventions to positively impact on exertional dyspnoea and to select rehabilitative strategies with low-to-minimal ventilator stress [7]. The results reported in this issue of the European Respiratory Journal and in previous papers suggest that overlap patients are particularly prone to responding to interventions that increase skeletal muscle $\mathrm{O}_{2}$ delivery and/or reduce $\mathrm{O}_{2}$ demand $[11,12]$. Such leg muscle oxygenation during exercise can also be achieved by respiratory muscle unloading by noninvasive positive pressure ventilation [15]. Longitudinal assessment of ventilatory inefficiency may be very helpful to understand progress of disability in COPD patients. Furthermore, the authors clearly demonstrate the limited value of staging COPD patients only based on the degree of airflow limitation [5].

For targeted intervention strategies aiming to reduce dyspnoea through pulmonary rehabilitation or lung volume reduction procedures, understanding the pathophysiological mechanisms underlying patients' disability is paramount to mitigating symptom burden and improving health status in these patients [16]. Such targeted intervention requires an interdisciplinary cardiorespiratory approach. Ignoring the underlying mechanisms behind reported symptomatology by the patient will stifle personalised developments in COPD management.

Conflict of interest: E.F.M. Wouters reports personal fees for board membership from Nycomed and Boehringer, personal fees for lecturing from AstraZeneca, GSK, Novartis and Chiesi, and grants from AstraZeneca and GSK.

\section{References}

1 Global Initiative for Chronic Obstructive Lung Disease (GOLD). Global Strategy for Prevention, Diagnosis and Management of COPD. 2019. Available from https://goldcopd.org/

2 Agusti A, Compte A, Faner R, et al. The EASI model: a first integrative computational approximation to the natural history of COPD. PLoS One 2017; 12: e0185502.

3 American Thoracic Society/European Respiratory Society. ATS/ERS Statement on respiratory muscle testing. Am J Respir Crit Care Med 2002; 166: 518-624.

4 Rocha A, Arbex FF, Sperandio PA, et al. Exercise intolerance in comorbid COPD and heart failure: the role of impaired aerobic function. Eur Respir J 2019; 53: 1802386. 
5 Neder JA, Arbex FF, Alencar MC, et al. Exercise ventilatory inefficiency in mild to end-stage COPD. Eur Respir J 2015; 45: 377-387.

6 Arbex FF, Alencar MC, Souza A, et al. Exercise ventilation in COPD: influence of systolic heart failure. COPD 2016; 13: 693-699.

7 Rocha A, Arbex FF, Sperandio PA, et al. Excess ventilation in chronic obstructive pulmonary disease-heart failure overlap. Implications for dyspnea and exercise intolerance. Am J Respir Crit Care Med 2017; 196: 1264-1274.

8 Aliverti A, Dellaca RL, Lotti P, et al. Influence of expiratory flow-limitation during exercise on systemic oxygen delivery in humans. Eur J Appl Physiol 2005; 95: 229-242.

9 Aliverti A, Macklem PT. The major limitation to exercise performance in COPD is inadequate energy supply to the respiratory and locomotor muscles. J Appl Physiol 2008; 105: 749-751.

10 Poole DC, Hirai DM, Copp SW, et al. Muscle oxygen transport and utilization in heart failure: implications for exercise (in)tolerance. Am J Physiol Heart Circ Physiol 2012; 302: H1050-H1063.

11 Oliveira MF, Arbex FF, Alencar MC, et al. Heart failure impairs muscle blood flow and endurance exercise tolerance in COPD. COPD 2016; 13: 407-415.

12 Rocha A, Arbex FF, Alencar MC, et al. Physiological and sensory consequences of exercise oscillatory ventilation in heart failure-COPD. Int J Cardiol 2016; 224: 447-453.

13 Mesquita R, Franssen FM, Houben-Wilke S, et al. What is the impact of impaired left ventricular ejection fraction in COPD after adjusting for confounders? Int J Cardiol 2016; 225: 365-370.

14 van Geffen WH, Slebos DJ, Herth FJ, et al. Surgical and endoscopic interventions that reduce lung volume for emphysema: a systemic review and meta-analysis. Lancet Respir Med 2019; 7: 313-324.

15 Borghi-Silva A, Oliveira CC, Carrascosa C, et al. Respiratory muscle unloading improves leg muscle oxygenation during exercise in patients with COPD. Thorax 2008; 63: 910-915.

16 Spruit MA, Wouters EFM. Organizational aspects of pulmonary rehabilitation in chronic respiratory diseases. Respirology 2019; in press [https://doi.org/10.1111/resp.13512]. 